(6) OPEN ACCESS

Correspondece to

Mitch Zeller, Pinney Associates, 4800 Montgomery Lane, Suite

400, Bethesda,

MD 20814, USA;

mzeller@pinneyassociates.com

Received 18 September 2012 Revised 19 December 2012

Accepted 2 January 2013
To cite: Zeller M. Tob Control 2013;22:i40-i41.

\title{
Reflections on the 'endgame' for tobacco control
}

\author{
Mitch Zeller
}

The concept of an 'endgame' for tobacco control efforts is receiving increasing attention in advocacy, policy and academic circles. This may strike some as entirely premature in countries such as Bangladesh, where $63 \%$ of adults are exposed to secondhand smoke in the workplace, ${ }^{1}$ or the Russian Federation, where $60 \%$ of adult men still smoke. $^{2}$

Nonetheless, experts in countries like Australia and New Zealand, with a decades-long commitment to comprehensive tobacco control, have grown increasingly serious about the so-called 'endgame'.

Numerous potential endgame strategies are being explored, the most prominent of which are chronicled elsewhere in this supplement. We have yet to reach a consensus on which one or two strategies should be pursued. But when a group of global thought leaders gathered in 2012 to consider the endgame, there was convergence around the notion that we need new approaches to dramatically reduce consumption of conventional combusting cigarettes, if not other tobacco products that burn.

If such an approach is to succeed, it will be because policy makers and tobacco control advocates have overcome their reluctance and finally embraced a concept known as the 'continuum of risk'. Over time, many policy thinkers-this author included-have seen their views on these issues evolve in just such a manner.

There is a spectrum or continuum of tobacco and medicinal products that aim to do the same thing-deliver nicotine to the user. But the toxicity associated with those products varies dramatically. At one end of the spectrum is the conventional cigarette, which is designed quite deliberately to create and sustain an addiction to nicotine. Smoke particles deliver nicotine to the lungs and through the bloodstream to the brain in less than $10 \mathrm{~s}$. Cigarettes kill half of all long-term users and are expected to claim the overwhelming majority of the projected 1 billion deaths from tobacco in this century if trends continue. ${ }^{3}$

At the other end of the spectrum is the current generation of medicinal nicotine products such as gum, patches and lozenges. Made without tobacco (though the nicotine is derived from tobacco), these products pose significantly less risk and have been approved by regulatory bodies around the world as both safe and effective for tobacco cessation.

Along the path of the continuum of risk are products that pose less harm to the individual than cigarettes but for which less is known about their population-level health impacts. Here, we would place smokeless and dissolvable tobacco products as well as the 'e-cigarette'.
Anyone who would ponder the endgame must acknowledge that the continuum of risk exists and pursue strategies that are designed to drive consumers from the most deadly and dangerous to the least harmful forms of nicotine delivery. Just such an approach has been embraced by the Medicines Agency in the UK. If the phrase 'harm reduction' is too off-putting for endgame seekers, then let us collectively agree to a different phrase but one that still embraces the policy implications of the continuum of risk.

The late Michael Russell said decades ago that people smoke for the nicotine but die from the tar. ${ }^{4}$ This powerful insight remains extremely relevant today and should drive much of our 'endgame' thinking. But whereas tobacco product regulation was virtually nonexistent when Dr Russell offered up his observation in the 1970s, today, science-based regulation of all tobacco products is possible in the USA and globally either through enacted legislation or under the relevant provisions of the Framework Convention on Tobacco Control.

Effective product regulation holds enormous promise as a means towards accomplishing endgame objectives. One such approach is receiving serious consideration in the USA. With passage in 2009 of the Family Smoking Prevention and Tobacco Control Act, ${ }^{5}$ the US Food and Drug Administration (FDA) now has the authority to issue mandatory product standards to control permissible levels of compounds in tobacco products. ${ }^{6}$ This includes the power to render cigarettes nonaddictive by ordering the nicotine content down below a threshold level of addiction, so long as the FDA does not reduce nicotine levels to zero. ${ }^{7}$ Promising research is underway that may soon provide the evidence base needed for mandatory reductions in nicotine content in combustible tobacco products.

In most countries, the goal of coordinated tobacco control efforts should centre on the dramatic reduction or elimination of combustible tobacco use. Product regulation is a critical component of any comprehensive approach to reduce tobacco use. But with the advent of regulation, will the government be a key facilitator or barrier to the effective implementation of strategies designed to achieve this public health goal?

After three-plus years following enactment of the Family Smoking Prevention and Tobacco Control Act, the performance of the FDA has been mixed. ${ }^{8}$ Will agencies like the FDA be up to the task of using their new-found regulatory powers to alter tobacco products and the marketplace in which they are sold so that endgame strategies have the best possible change of succeeding? 
This is a complex question. It certainly has a political dimension that cannot be ignored. For example, will regulators be able to withstand the inevitable political pressure they will experience from politicians sympathetic to the tobacco industry? Globally, it means that part of the challenge is to ensure that regulators have sufficient resources to get the job done.

Ultimately, these regulatory challenges are also a reminder to 'endgame' enthusiasts that we have an obligation to arm regulatory agencies with the strongest possible evidence base to support policy change, while simultaneously holding the regulators accountable to make sure that the evidence base is used effectively to help reduce the death and disease caused by tobacco use.

\section{Key messages}

- Any evaluation of endgame strategies must start from the premise that there is a continuum of risk associated with nicotine-delivering products.

- Strategies should be pursued that encourage the use of the cleanest and safest form of nicotine delivery.

- Product regulation can play an important rule in any endgame approach.
Competing interests The author is employed by Pinney Associates, a health policy consulting firm. Pinney Associates provides consulting services to GlaxoSmithKline Consumer Healthcare on issues related to the treatment of tobacco dependence.

Provenance and peer review Not commissioned; externally peer reviewed.

Open Access This is an Open Access article distributed in accordance with the Creative Commons Attribution Non Commercial (CC BY-NC 3.0) license, which permits others to distribute, remix, adapt, build upon this work non-commercially, and license their derivative works on different terms, provided the original work is properly cited and the use is non-commercial. See: http://creativecommons.org/licenses/by-nc/3.0/

\section{REFERENCES}

1 Campaign for Tobacco-Free Kids (CTFK). Global epidemic.Bangladesh. Washington DC: CTFK, 2012. http://global.tobaccofreekids.org/en/global_epidemic/bangladesh (accessed 17 Sep 2012)

2 Campaign for Tobacco-Free Kids (CTFK). Global epidemic. Russian Federation. Washington DC: CTFK, 2012. http://global.tobaccofreekids.org/en/global_epidemic/ russian_federation/ (accessed 17 Sep 2012).

3 WHO.Tobacco Free Initiative (TFI). Tobacco facts. Geneva: WHO, 2012. http://www. who.int/tobacco/mpower/tobacco_facts/en/index.html (accessed 17 Sep 2012).

4 Russell MA. Low-tar medium-nicotine cigarettes: a new approach to safer smoking. BMJ 1976;1:1430-3.

5 The Family Smoking Prevention and Tobacco Control Act. Public Law 111-31, H.R. 1256. 22 June, 2009.

6 Family Smoking Prevention and Tobacco Control Act Section 907.

7 Family Smoking Prevention and Tobacco Control Act Section 907(d)(3).

8 Zeller M. Three years later: an assessment of the implementation of the Family Smoking Prevention and Tobacco Control Act. Tob Control 2012;21:3-4. 